\title{
Impact of Global Value Chain Embedding on Total-Factor Energy Productivity of Chinese Industrial Sectors
}

\author{
Xiwen Feng, ${ }^{1}$ Mingshang Xin $\mathbb{D}^{1},{ }^{1,2}$ and Xinghua $\mathrm{Cui}^{3}$ \\ ${ }^{1}$ College of Mining and Safety Engineering, Shandong University of Science and Technology, Qingdao, Shandong 266590, China \\ ${ }^{2}$ State Key Laboratory of Mining Disaster Prevention and Control Co-founded by Shandong, \\ Province and the Ministry of Science and Technology, Shandong University of Science and Technology, Qingdao, \\ Shandong 266590, China \\ ${ }^{3}$ School of Economics, Jiangxi University of Finance and Economics, No. 169, Shuanggang East Street, \\ Economic Development Zone, Qingshanhu, Nanchang, Jiangxi, China
}

Correspondence should be addressed to Mingshang Xin; xinmingshang1989@163.com

Received 9 January 2020; Revised 12 June 2020; Accepted 19 June 2020; Published 15 July 2020

Academic Editor: Pallav Purohit

Copyright (C) 2020 Xiwen Feng et al. This is an open access article distributed under the Creative Commons Attribution License, which permits unrestricted use, distribution, and reproduction in any medium, provided the original work is properly cited.

In the four decades since China's reform and opening up, China has been playing an active role in global value chain (GVC) due to its abundant resources. China has gained enormous benefits from opening up, but has also suffered huge energy costs in the process. In this study, we incorporated global value chains and energy consumption into a unified analysis framework and calculated the energy totalfactor productivity (ETFP) of China's industry and the degree of participation in GVC. In addition, in order to discover the contradictions and problems between China's participation in global value chains and the improvement of total energy factor productivity, the panel smooth transformation model (PSTR) was used to empirically test the nonlinear relationship between the ETFP and the degree of participation in GVC in China. From the analysis results, GVC participation, as well as the subdivided shallow GVC participation and deep GVC participation, first promoted the effect on ETFP and then suppressed it, showing an inverted U-shaped single threshold characteristic. The results indicated that in the progress of starting to participate in the GVC, the effect of technological progress of the GVC overweighed the scale effect of energy consumption, resulting in the growth of ETFP. However, due to the gradual reduction of technology dividends and the "low-end lock-in" situation, China was placed in the value chain by the developed countries, and the technological effect was gradually smaller than the scale effect of energy consumption. As a result, the increase in the total-factor productivity of energy was inhibited. At the same time, in the further examination of industry heterogeneity, the inverted U-shaped influence trend was more significant in high energy-consuming industries. The conclusions of this study can provide a new perspective and policy focus for China's participation in GVC to achieve the goal of increasing ETFP.

\section{Introduction}

Since the 1990s, the global value chain (GVC) has become the new normal for global economic development, greatly changing the form and pattern of international division of labor [1]. As the world's largest manufacturing plant, China is playing an increasingly important role in the new international division of labor system of GVCs. The embedding of GVC in China has been greatly improved. On the one hand, for most developing countries, including China, participating in GVC can help improve their technological and industrialization levels, thereby promoting their economic growth. On the other hand, developed countries or regions that dominate GVCs may transfer pollutionintensive production links to developing countries and put developing countries under tremendous environmental pressures. With the gradual loss of demographic dividend and the increasing shortage of resources, the industrial economy of China starts falling into the "bottleneck" of development. At the same time, in the context of global warming, Chinese industry is facing increasing pressure on energy and environment.

For a long time, large multinational companies in developed countries have firmly occupied the high end of the 
value chain, while Chinese manufacturing industry faces the risk of being locked at the low end of the value chain. With the continuous deepening of China's reform and opening up, under the new international division of labor system of GVC, it is particularly important for China to realize the transformation of industry from the low end to the high end [2-4]. Therefore, to achieve high-quality and sustainable development of Chinese industry, we must shift from the traditional extensive growth model that relies on high energy consumption and high emissions to the intensive growth model that focuses on quality and efficiency.

Therefore, the correct understanding of the relationship between the embedding of GVC and the ETFP in Chinese industrial sector is particularly important. At present, the relevant studies in China and other countries are mainly focused on the following two aspects: firstly, the impact of GVC embedding on total-factor productivity or technological progress was investigated. Based on the spillover effects and feedback effects between industries, Egger [5] performed empirical research using Austrian panel data [5] and concluded that the embedding degree of GVC had a "Ushaped" relationship with industrial productivity. Amiti and Wei [6] reported that production efficiency can be improved through multiple methods such as learning effects and efficiency improvement effects. In addition, through empirical analysis, they concluded that embedded GVCs had significantly improved the productivity of the manufacturing industry in the USA [6]. Yanning Chen pointed out that increasing the participation of GVC in the power industry can help improve the predictability and attractiveness of investment and technology transfer [7]. Flent and Ponte believed that for the least developed countries, increasing the participation of GVC in the industrial sector can help increase the industrial factor productivity [8]. Jay Sterling Gregg et al. conducted a case study to analyze CE (cellulosic ethanol) manufacturing plants in various places in Europe from the perspective of GVC. They found that the embedding of GVC can effectively improve the industry productivity [9]. Secondly, the impact of GVC embedding on the energy factor productivity of the industry was investigated. Dean and Lovely [10] claimed that participating in the international division of labor can help reduce the pollution intensity of China's foreign trade [10]. Marchi et al. used the development of Italian furniture industry as an example and reported the important relationship between the participation of GVC and the improvement of environmental performance [11]. Pierluigi et al. investigated the enterprises in Latin American and Caribbean countries and found a positive correlation between the participation in international activities and corporate performance [12]. Ge et al. used the data between 2000 and 2007 to measure the embedding degree of Chinese enterprises in GVCs. Then, the impact of enterprises' participation in GVC on the productivity was investigated using entropy balance method. The results showed that the embedding in GVC significantly improved the productivity of Chinese manufacturing enterprises [13].

This study expands and extends the existing research from the following aspects: firstly, this study calculated the
ETFP in China's industrial sectors and investigated the relationship between GVC and the ETFP from a macroperspective. Secondly, this study used the DEA-Malmquist index method to measure the ETFP in various industrial sectors. Meanwhile, the row equilibrium conditions in the global multiregion input-output table were used to measure the embedding degree of GVC. In addition, this study examined the internal connection between GVC and EFTP using the two-zone panel smooth transition model (PSTR) and passed the industry heterogeneity test and robustness test.

The rest of the paper is organized as follows: Section 2 provides the research hypothesis; Section 3 introduces the variables, data description, and model construction; Section 4 explains the empirical results and analysis; Section 5 provides the research conclusions and policy recommendations.

\section{Research Hypothesis}

2.1. Promoting Effect of GVC Embedding on ETFP. GVC can affect the ETFP in the following ways: (1) From the perspective of exports, GVC-led companies pass high standards such as quality, safety, environmental protection, and product style to foundry companies, forcing them to learn the technology, management, organizational capabilities, and social institutions and catch up with the developed countries $[9,14,15]$. Thus, participation in GVC can enhance the innovation capabilities of the foundry companies to meet the high demands of foreign consumers. (2) From the perspective of imports, on the one hand, importing intermediate investment products leading the value chain from developed countries, such as advanced machinery and raw materials, can directly improve labor productivity in developing countries through input-output effects. On the other hand, developing countries can learn and assimilate existing technologies from developed countries at a low cost to achieve their own technological progress $[16,17]$. (3) The separation and integration of GVC have enabled local Chinese companies that are not familiar with the operation of the international market to integrate into the global production division system organized by multinational companies. On the one hand, the local Chinese companies can obtain the precious learning and training opportunities. On the other hand, these companies accept the supervision and help from multinational companies [18-20]. This study refers to the effect of the abovementioned GVC embedding as the "Push Effect," which leads to the improvement of ETFP. Based on the discussion, the following hypothesis is proposed.

Hypothesis 1 (H1). GVC embedding is conducive to promote the improvement of ETFP in the industrial sector.

2.2. Suppression Effect of GVC Embedding on the ETFP. The suppression effect of the GVC embedding on the improvement of the ETFP can be reflected in three aspects: (1) China mainly exports technologically mature or labor-intensive 
products with the advantage of low cost, which is easily "captured" by large international buyers and multinational companies who dominate the GVC. As a result, Chinese export companies are forced to be locked in production mode and technology path with reduced production costs, and thus, the technological progress and the improvement of the ETFP are inhibited [21, 22]. (2) When the Chinese companies are transitioning from the low-end link of GVC to the high-end link, especially after undergoing functional upgrades or chain upgrades, they are double-blocked and controlled by large international buyers or multinational companies in developed countries. As a result, the Chinese companies are locked in the production chain at the low end of the value chain with low added value and low profit, while developed countries firmly control the high-end of the value chain and the strategic core links by controlling R\&D and design, high-end channel integration, and strategic resources $[2,23]$. (3) Compared with developed countries, the absorptive capacity of Chinese enterprises is limited by various factors, including the availability of knowledge, economic level, social factors, cultural factors, and political factors. For example, the absence of intellectual property protection systems and enforcement mechanisms in Chinese companies has severely limited their absorption and innovation ability $[14,24]$. Based on the discussion in this paragraph, the following hypothesis is proposed.

Hypothesis 2 (H2). The dual effects of GVC embedding result in a nonlinear relationship between GVC embedding and the increase in total-factor energy productivity of the industry.

\subsection{Hypothesis on the "Inverted U-Shaped" Relationship be-} tween GVC Embedded and ETFP. GVC led by large international buyers and multinational corporations adopts the "carrot and stick" strategy for the companies in developing countries: (1) The value chain owner provides supervision and assistance to developing countries through high-quality, safe, and environmentally friendly import requirements. Developing countries can obtain rapid process and product upgrades through the learning effect. As a result, the technological progress in developing countries can be promoted and the total-factor energy productivity of enterprises can be improved [25-27]. (2) When the foundry production system in developing countries enters the stage of functional upgrade or chain upgrade and tries to establish its own core technology research and development capabilities, the monopoly power and vested interests of value chain owners will be challenged. Then the value chain owners will hinder and control foundry enterprises from achieving higher-level functional upgrades and chain upgrades, thereby inhibiting the technological progress of the developing countries and forcing developing countries to be locked at the low-end links of GVC. When the embedding of GVC in developing countries reaches a certain "threshold," the push effect is less significant than the inhibitory effect, and GVC reverses the energy factor productivity [28-31]. Thus, the following hypothesis is proposed:

Hypothesis 3 (H3). With the deepening of GVC in the industrial industry, the driving effect is continuously diminished, while the blockade and restrictions from developed countries lead to the suppression effect. Therefore, there is an inverted U-shaped nonlinear relationship between the embedding of GVC and the ETFP.

\section{Variables, Data Description, and Model Construction}

3.1. Calculation of ETFP. In this study, the DEA-Malmquist index method was used to calculate the ETFP.

(1) DEA Model: the DEA method is one of the main methods to evaluate efficiency, which includes the CCR model (assuming constant returns to scale) and the BCC model (assuming variable returns to scale). The CCR model can be expressed by the following equation:

$$
\begin{aligned}
& \operatorname{Min}\left\{\theta-\varepsilon\left(\hat{e^{T}} \mathrm{~s}^{-}+\hat{e^{T}} s^{+}\right)\right\}, \\
& \text {s.t. }\left\{\begin{array}{l}
\sum_{j=1}^{n} X_{j} \lambda_{j}+S^{-}=\theta X_{0}, \\
\sum_{j=1}^{n} X_{j} \lambda_{j}-S^{+}=Y_{0}, \\
\lambda_{j} \geq 0, j=1,2, \cdots, n, \\
S^{-} \geq 0, S^{+} \geq 0
\end{array}\right.
\end{aligned}
$$

where $\theta$ is the target value of linear programming, $\lambda_{j}$ is the decision weight, and $S^{-}$and $S^{+}$are relaxation variables. The decision unit is valid at the settings of $\theta=1$ and $S^{-}=0, S^{+}=0$. Otherwise, the decision unit is not valid, and there is redundant input or insufficient output. (2) Malmquist exponential model: in order to investigate the trend of energy efficiency in different periods, the Malmquist index was used to calculate the ETFP and its factor decomposition. After obtaining the directional distance function through the above DEA linear programming, the Malmquist index of the $t$-th to $(t+1)$-th periods of the $r$ decision unit can be calculated as follows:

$$
M\left(x_{r}^{t+1}, y_{r}^{t+1}, x_{r}^{t}, y_{r}^{t}\right)=\frac{D^{t}\left(x_{r}^{t}, y_{r}^{t}\right)}{D^{t+1}\left(x_{r}^{t+1}, y_{r}^{t+1}\right)} \times\left[\frac{D^{t+1}\left(x_{r}^{t}, y_{r}^{t}\right)}{D^{t}\left(x_{r}^{t+1}, y_{r}^{t+1}\right)} \times \frac{D^{t+1}\left(x_{r}^{t+1}, y_{r}^{t+1}\right)}{D^{t}\left(x_{r}^{t}, y_{r}^{t}\right)}\right]^{\frac{1}{2}},
$$

where $M>1$ represents the growth of total-factor productivity and $M<1$ represents the decline of total-factor productivity.
The data on the output value of industrial subsectors are only published until 2011, and the total output value of each subsector is no longer published after 2012. Therefore, this 
study took examples from Liu et al. $[4,16]$ and used the industrial sales output value, which was close to the total industrial output value to calculate ETFP. According to the method adopted by most scholars, the factors including capital, labor, and energy were selected as input factors $[2,4,16]$. In addition, in this study, the labor force variable was replaced by the average number of employees in the Chinese industry, which was obtained from China Industry Statistical Yearbook 2001-2014. Considering the lack of employment in the industrial sector between 2004 and 2012, the data were completed with the linear interpolation method. The capital stock was calculated using the perpetual inventory method, which can be expressed by the following equation: $K_{t}=K_{t-1}\left(1-\delta_{t}\right)+\left(I_{t} / P_{t}\right)$, where $K_{t}$ and $K_{t-1}$ represent the capital stock in period $t$ and $t-1$, respectively. Energy input was expressed by the energy consumption of various industrial sectors $[17,18]$.

The average ETFP growth index of China's industrial sectors from 2001 to 2014 is shown in Figure 1. From Figure 1, the growth index of the ETFP is greater than 1 only in the pharmaceutical manufacturing industry. Thus, the ETFP in most Chinese industrial sectors has declined, especially in the high energy consumption industries such as electricity, heat production and supply, metal products, and extractive industries.

3.2. Measurement of GVC Participation. Based on the calculation method reported by Wang et al. [24], in this study, the global multiregion input-output table can be described using the global equilibrium conditions in the multiregion input-output table, as shown in the following equation:

$$
X^{i}=A^{i i} X^{i}+\sum_{j \neq i} A^{i j} X^{i}+Y^{i i}+\sum_{j \neq i} Y^{i j}=A^{i i} X^{i}+Y^{i i}+E^{i^{*}} \text {, }
$$

where $E^{i^{*}}$ is the total export column vector of economy $I$. Equation (3) can be rewritten as follows:

$$
\begin{aligned}
X^{i} & =\left(I-A^{i i}\right)^{-1} Y^{i i}+\left(I-A^{i i}\right)^{-1} E^{i^{*}}=L^{i i} Y^{i i}+L^{i i} E^{i^{*}} \\
& =L^{i i}\left(Y^{i i}+E^{i^{*}}\right),
\end{aligned}
$$

where $\left(I-A^{i i}\right)^{-1}$ is a local inverse matrix. Furthermore, according to the purpose of intermediate products, final products, and final absorption, the total exports can be decomposed as follows:

$$
\begin{aligned}
L^{i i} E^{i^{*}} & =L^{i i}\left(\sum_{j \neq i}^{G} Y^{i j}+\sum_{j \neq i}^{G} A^{i i} X^{j}\right) \\
& =L^{i i} \sum_{j \neq i}^{G} Y^{i j}+L^{i i} \sum_{j \neq i}^{G} A^{i i} X^{j} \\
& =L^{i i} \sum_{j \neq i}^{G} Y^{i j}+L^{i i} \sum_{j \neq i}^{G} A^{i j} \sum_{k}^{G}\left(B^{j k} \sum_{l}^{G} Y^{k l}\right),
\end{aligned}
$$

where $B^{j k}$ is the block matrix of the Leontief inverse matrix. The value-added coefficient vector is defined as $V=V_{a} \widehat{X}^{-1}$, where $\widehat{X}$ is a diagonal matrix corresponding to the matrix $X$. Substituting (5) into (4) and multiplying both sides with the added value diagonal matrix $\widehat{V}$, the value added (GDP) of the national industry sector can be decomposed into the following five parts:

$$
\begin{aligned}
\left(V_{a}^{i}\right)^{\prime}= & \widehat{V}^{i} X^{i}=\widehat{V^{i}} L^{i i} Y^{i i}+\widehat{V}^{i} L^{i i} E^{i^{*}}=\widehat{V}^{i} L^{i i} Y^{i i}+\widehat{V^{i}} L^{i i} \sum_{j \neq i}^{G} Y^{i j} \\
& +\widehat{V}^{i} L^{i i} \sum_{j \neq i}^{G} A^{i j} \sum_{k}^{G}\left(B^{j k} \sum_{l}^{G} Y^{k l}\right), \\
& \cdot(1)-V_{-} D, \quad(2)-V_{-} R T, \quad(3)-V_{-} G V C, \\
= & \widehat{V}^{i} L^{i i} Y^{i i}+\widehat{V^{i}} L^{i i} \sum_{j \neq i}^{G} Y^{i j}+\widehat{V^{i}} L^{i i} \sum_{j \neq i}^{G} A^{i j} L^{i i} Y^{i i} \\
& +\widehat{V}^{i} L^{i i} \sum_{j \neq i}^{G} A^{i j} \sum_{k}^{G}\left(B^{j k} Y^{k i}\right) \\
& +\left[\widehat{V}^{i} L^{i i} \sum_{j \neq i}^{G} A^{i j} \sum_{k}^{G}\left(B^{j k} \sum_{l \neq i}^{G} Y^{k l}\right)-\widehat{V}^{i} L^{i i} \sum_{j \neq i}^{G} A^{i j} L^{i i} Y^{i i}\right], \\
& \cdot(1)-V_{-} D, \quad(2)-V_{-} R T, \quad(3 a)-V_{-} G V C_{-} R, \\
& \cdot(3 b)-V_{-} G V C_{-} D, \quad(3 c)-V_{-} G V C_{-} F .
\end{aligned}
$$

According to (6), the domestic value added (or GDP) of the state sector consists of the following three types of production activities:

(1) The value added that meets domestic production and consumption $\left(\widehat{V}^{i} L^{i i} Y^{i i}\right)$, expressed as $V_{-} D$.

(2) The domestic value added $\left(\widehat{V}^{i} L^{i i} \sum_{j \neq i}^{G} Y^{i j}\right)$ implied in the final demand export, expressed as $V_{-} R T$.

(3) The domestic value added implied in the export of intermediate products, expressed as $\left(\widehat{V}^{i} L^{i i} \sum_{j \neq i}^{G} A^{i j} \sum_{k}^{G}\left(B^{j k} \sum_{l}^{G} Y^{k l}\right)\right)$. This type of the value added participates in the foreign production process, which can be represented by $V_{-} G V C$. Furthermore, considering the way and the position of the final demand to absorb this domestic value added, this value added in this category can be further divided into three parts: (a) the domestic value added directly absorbed by partner country, expressed as $\left(\widehat{V}^{i} L^{i i} \sum_{j \neq i}^{G} A^{i j} L^{i i} Y^{i i}\right)$; (b) the added value returned to the exporting country and absorbed by final demand, expressed as $\left(\widehat{V}^{i} L^{i i} \sum_{j \neq i}^{G} A^{i j}\right.$ $\left.\sum_{k}^{G}\left(B^{j k} Y^{k i}\right)\right)$; and (c) the domestic value added indirectly absorbed by or exported to a third country, expressed as $\left(\widehat{V}^{i} L^{i i} \quad \sum_{j \neq i}^{G} A^{i j} \quad \sum_{k}^{G}\left(B^{j k} \sum_{l \neq i}^{G} Y^{k l}\right)-\right.$ $\left.\widehat{V^{i}} L^{i i} \sum_{j \neq i}^{G} A^{i j} L^{i i} Y^{i i}\right)$.

Through the forward decomposition of the value added (GDP) at the national sector level in the above sections, the GVC participation index can be calculated by the following equation: 


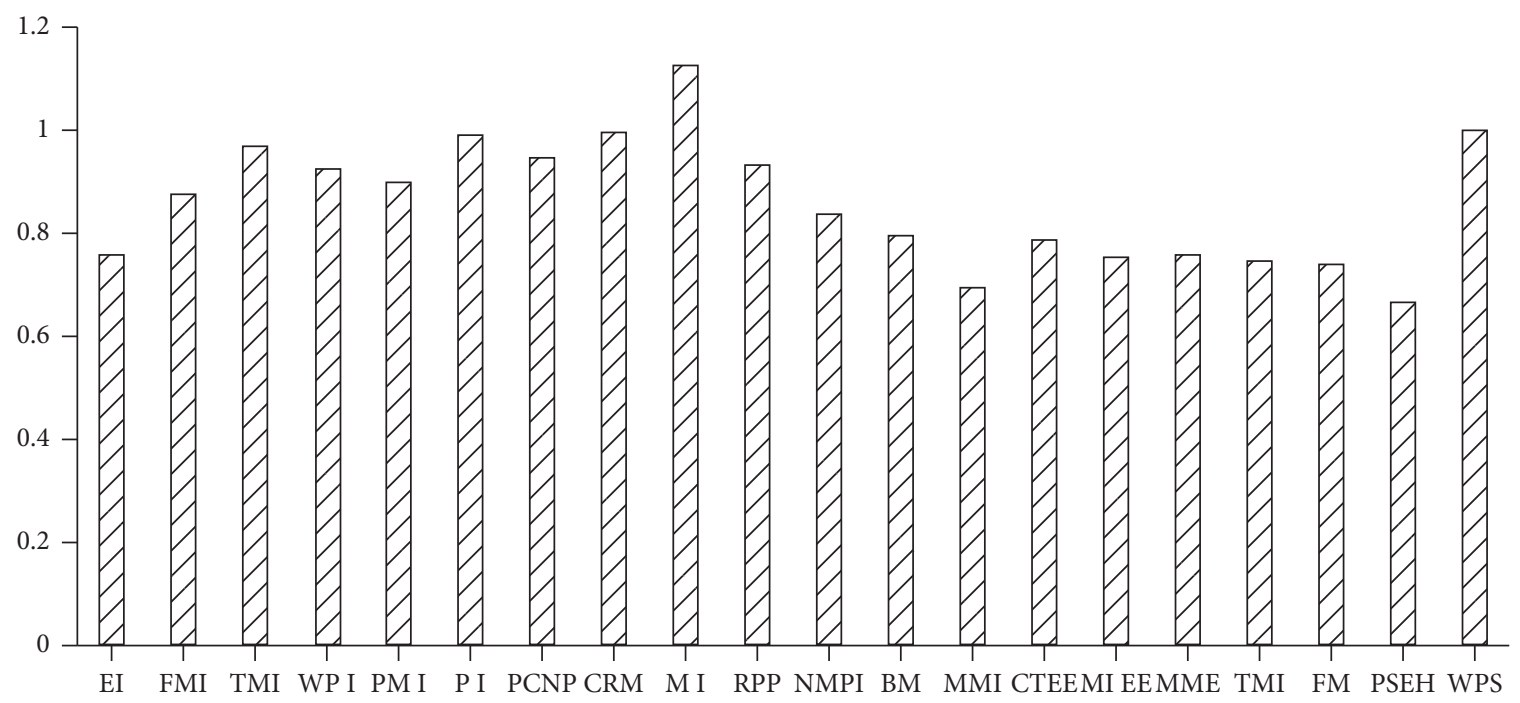

FIgURE 1: The ETFP growth index in China's industrial sector, 2001-2014.

$$
\begin{aligned}
G V C P_{-} f^{i}= & \frac{V_{-} G V C^{i}}{\widehat{V}^{i} X^{i}}=\frac{V_{-} G V C_{-} R^{i}}{\widehat{V}^{i} X^{i}}+\frac{V_{-} G V C_{-} D^{i}}{\widehat{V}^{i} X^{i}} \\
& +\frac{V_{-} G V C_{-} F^{i}}{\widehat{V}^{i} X^{i}},
\end{aligned}
$$

where $\mathrm{GVCP}_{-} f^{i}$ refers to the GVC participation index based on forward correlation.

In addition to the methodology, this study also draws on the previous studies $[19,20]$. According to the number of intermediate products transferred between countries, the participation degree of GVCs can be divided into simple GVC production activities and complex GVC production activities, which can be expressed by equations 8 and 9 , respectively:

$$
\begin{aligned}
G V C P_{-} S & =\frac{V \_G V C_{-} R^{i}}{\widehat{V}^{i} X^{i}}, \\
G V C P_{-} C & =\frac{V \_G V C_{-} D^{i}}{\widehat{V}^{i} X^{i}}+\frac{V \_G V C_{-} F^{i}}{\widehat{V}^{i} X^{i}} .
\end{aligned}
$$

Figure 2 shows the trend of Chinese participation in GVCs from 2001 to 2014. In addition, the trends of shallow and deep GVC participation are also shown in Figure 2. From Figure 2, for most industries in China, the participation degree in GVC first increased, then had a significant decline in 2008, and finally had another gradual increase. The decline in the middle should be due to the impact of the global economic crisis in 2008. In addition, Chinese participation in shallow GVCs is higher than that in deep GVCs, which indicates that the participation of most Chinese industries in GVCs has been shallow.

Figure 3 shows the trend of GVC participation of various Chinese industrial sectors based on forward decomposition from 2001 to 2014 in China's industrial sectors. It can be seen that from 2001 to 2014, the GVC participation of the food, beverage, and tobacco products manufacturing industry has been at a low level with a relatively small change. The GVC participation of the computer, communications, and other electronic equipment manufacturing industry has always been at a high level and is not affected by the economic crisis. After the decline in 2008, the GVC embeddedness of the pharmaceutical manufacturing, transportation equipment manufacturing, water production, and supply industries has not increased, but has shown a further downward trend. Overall, the degree of GVC embedding in the medium- and high-tech industries has been increased, while the degree of GVC embedding in low-tech industries has been declined. The results proved that in the process of participating in the GVC, Chinese industrial sector is changing from low technology to high technology, and the industrial structure is gradually upgrading.

3.3. Establishment of Model. The two-zone panel smooth transition model (PSTR) can be expressed as follows:

$$
y_{i t}=\mu_{i}+\beta_{0}^{\prime} x_{i t}+\beta_{1}^{\prime} x_{i t} g\left(q_{i t} ; \gamma, c\right)+\varepsilon_{i},
$$

where $i=1,2, \ldots, N ; t=1,2, \ldots, T, g\left(q_{i t} ; \gamma, c\right)$ is the transfer function of the transfer variable $q_{i t}$ with the value range of 0 to $1 . q_{i t}$ is the transformation variable. The regression coefficient vector $\beta_{1}^{\prime} x_{i t} g\left(q_{i t} ; \gamma, c\right)$ is also a continuous function of the transformation variable $q_{i t} . \gamma$ is a smoothing parameter, which reflects the transition speed of the transfer function from one district to another, and $c$ is the conversion position parameter indicating where the conversion is generated. Generally, the transfer function has two forms, i.e., logic function and exponential function, as shown in the following equations:

$$
\begin{aligned}
& g\left(q_{i t} ; \gamma, c\right)=\left(1+\exp \left(-\gamma \prod_{j=1}^{m}\left(q_{i t}-c_{j}\right)\right)\right)^{-1}, \\
& g\left(q_{i t} ; \gamma, c\right)=1-e^{-\gamma\left(q_{i t}-c\right)^{2}},
\end{aligned}
$$

where $\gamma>0, c_{1} \leq c_{2} \leq \cdots \leq c_{m}$. When the conversion function in (11) is used, an LSTR model is established. Gonzalez et al. reported that the value of $m$ was usually considered to 


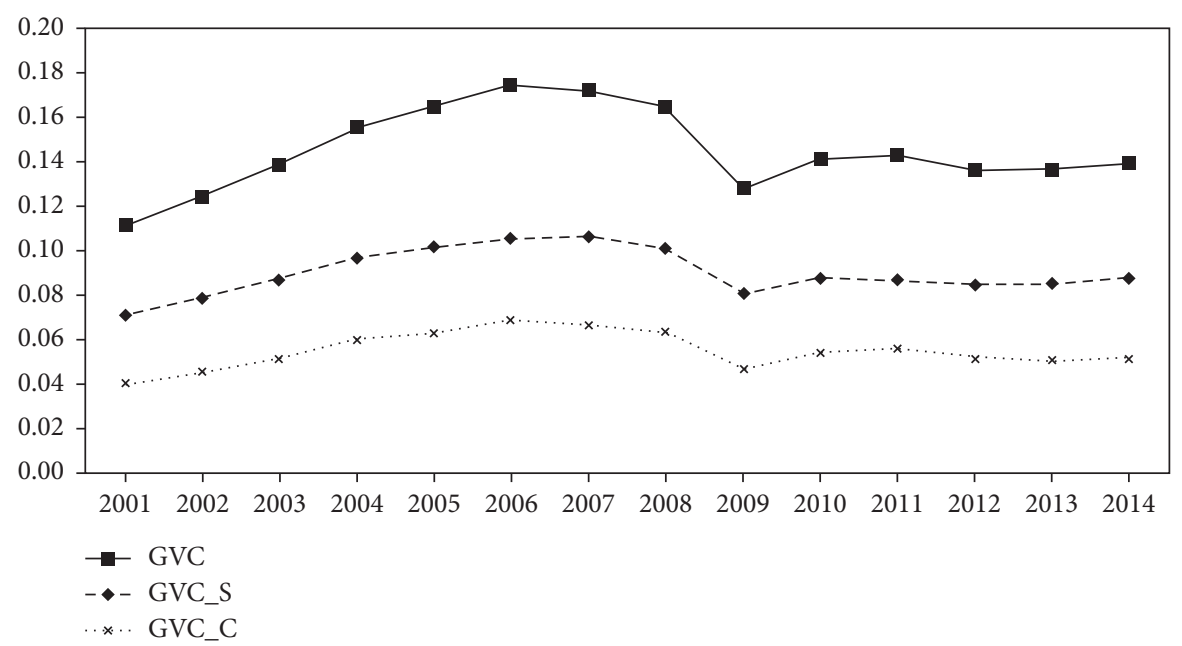

FIGURE 2: Trends of GVC participation.

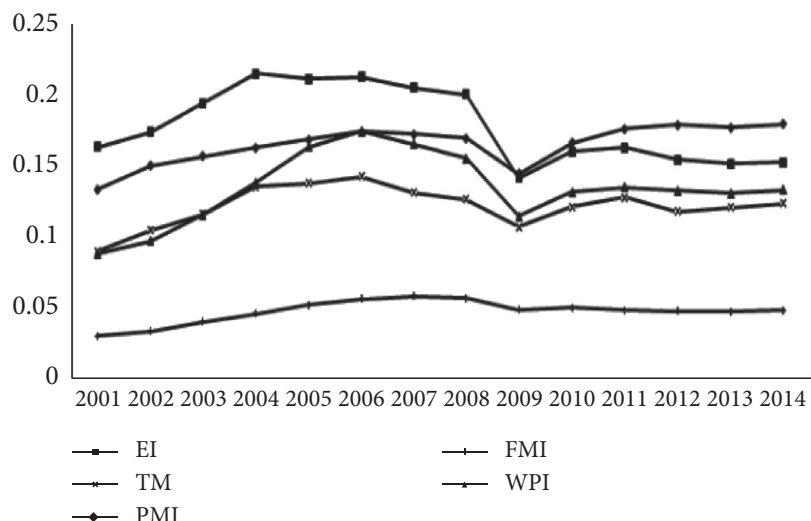

(a)

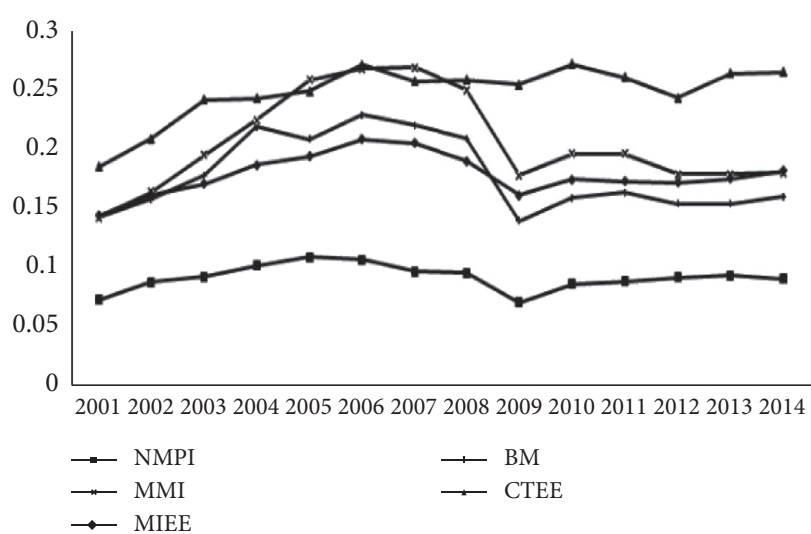

(c)

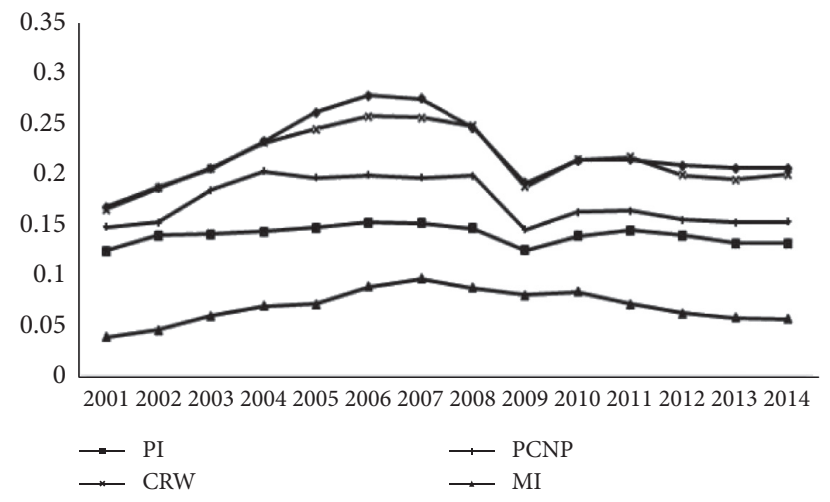

(b)

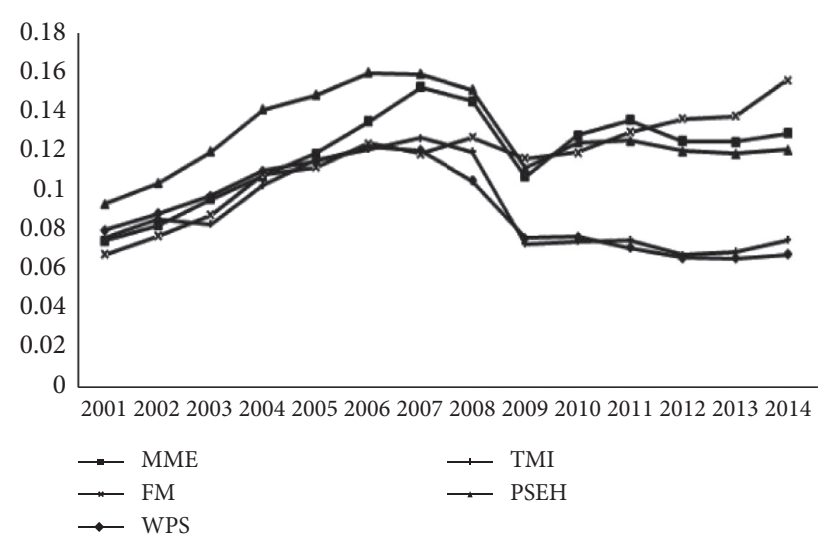

(d)

FIgURE 3: The trends of GVC participation of various industrial sectors in China from 2001 to 2014.

be 1 or 2 . When $m=1$, only one conversion position parameter exists in the model, $\underset{q_{i t} \longrightarrow-\infty}{\lim }=0, \underset{q_{i t} \stackrel{\lim }{\longrightarrow}+\infty}{ }=0$, and the smoothing of the conversion function is in the range of 0 to 1. When $m=2$, the panel smooth transition model can be considered as a three-zone model. When $\gamma \longrightarrow \infty$, the conversion function becomes a characteristic function, and the panel smooth transition model becomes a panel threshold (PTR) model. When $\gamma \longrightarrow 0$ or $q_{i t}=c$, $g\left(q_{i t} ; \gamma, c\right)=0.5$, the panel smooth transition model becomes a linear fixed-effect model. When the conversion function is expressed by equation (12), an ESTR model can 
be established. In the empirical analysis, the logical function is usually selected as the conversion function.

The general multisystem panel smooth conversion model can be expressed as follows:

$$
y_{i t}=\mu_{i}+\beta_{0}^{\prime} x_{i t}+\sum_{j=1}^{r} \beta_{j}^{\prime} x_{i t} g_{j}\left(q_{i t}^{j} ; \gamma, c\right)+\varepsilon_{i t},
$$

The parameters in this equation have the same meaning as (10).

In this study, ETFP was considered as the explanatory variable, which can be calculated using the DEA-Malmquist model described above. GVC was considered as the core explanatory variable. The remaining control variables are described as follows: (1) Foreign direct investment (FDI) is expressed by the actual amount of direct foreign investment utilized by various industries. (2) Export (EX) is expressed by the export delivery value of each industry. (3) The capital stock $(\mathrm{K})$ is measured by the perpetual inventory method. (4) Labor force (L) is expressed by the amount of employees in various industries. In this study, logarithmic values were used for all explanatory variables. As an important form of international industrial transfer, FDI was selected as a conversion variable in this study. In addition, $\alpha$ is a constant term vector, $\beta_{\mathrm{i}}$ is a coefficient vector, and $\varepsilon$ is a random interference term.

Furthermore, this study draws on relevant research results by Wang et al. and divided GVC participation into simple shallow GVC production (intermediate goods trade crosses borders once) and complex deep GVC production (intermediate goods crosses borders multiple times). Then a model with the shallow GVC participation as the core explanatory variable and a model with the deep GVC participation as the core explanatory variable were established. In addition, GVC_S was used to indicate the shallow GVC participation, and GVC_C was used to indicate the deep GVC participation. The rest of the variables have the same meaning as the baseline model.

Data source: the raw data of all variables in this study are from China Industry Statistical Yearbook, China Energy Statistics Yearbook, WIOD database, and UIBE GVC database. Considering the availability of data, the samples in this study were obtained in 15 periods from 2001 to 2014. The data in China Industrial Statistical Yearbook and China Energy Statistical Yearbook were classified according to the National Economic Industry Classification Standard (GB/ T4754-2002), and the WIOD database was classified based on the International Standard Industrial Classification (ISIC Rev.3.1). Therefore, the data from both sources were merged according to the matching guidelines in the United Nations website. Finally, 20 subindustries were obtained from the matched data, as shown in Table 1.

\section{Empirical Results and Analysis}

4.1. Benchmark Model Check. Firstly, in this study, the logical function was used, and a linear test and a residual nonlinear test were performed on the model. If the linear null hypothesis H0: $r=0$ is rejected, the model is considered to have nonlinear characteristics, and the residual nonlinear test needs to be continued to determine the optimal number of transfer functions. The test results are shown in Table 2 . From Table 2, the null hypothesis of the linear verification of the benchmark global value chain participation model is rejected by LM, LMF, and LRT statistics at a significance level of $1 \%$, indicating that the model had significant nonlinear characteristics. Therefore, it is reasonable to use the PSTR model in this study. In the residual nonlinear test, the null hypothesis of $r=1$ was statistically accepted according to all the three statistics, indicating that this model had 1 optimal transfer function. In the linear test of both the shallow GVC and the deep GVC participation models, the null hypothesis was rejected by LM, LMF, and LRT statistics at a significance level of $5 \%$, indicating that both models also had significant nonlinear characteristics. In the further residual nonlinear test, the null hypothesis of $r=1$ was accepted by all the three statistics, indicating that both models had 1 optimal transfer function. Therefore, according to the results in Table 3, all three models had 1 optimal position parameter. The last column of Table 3 shows the final number of transfer functions and the number of optimal parameter positions for each model.

4.2. Analysis of Benchmark Regression Results. After the optimal model was selected, Matlab 2014 was used to estimate the parameters of the PSTR model. Based on the research by Gonzalez et al. [21], the grid search method was used to obtain the initial values of the parameters $\gamma$ and $c$ and calculate the estimation value of these coefficients in the model. Then, NLS was used to estimate the model to minimize the sum of the squared residuals of the model. Through repeated iterations, the parameters were converged to obtain the optimal parameter estimates. The estimated results are shown in Table 4.

From Table 4, firstly, from the perspective of benchmark GVC participation model, the impact of GVC participation on ETFP had a single threshold characteristic. When the logarithm of FDI was below 5.0163, GVC participation can promote the total-factor energy productivity $\left(\beta_{0}^{\prime}=12.5704>0\right)$. When the logarithm of foreign direct investment reached the threshold of 5.0163, the impact of GVC participation on ETFP became negative with the coefficient of $-2.773745(12.5704-30.6157 \times 0.5)$. After the threshold was completely above 5.0163 , the impact of total-factor energy productivity was stable at -18.0443 (12.5704-30.6157), and it was significant at a significance level of $1 \%$. From the empirical results of the benchmark GVC participation model, it can be seen that with the continuous increase of FDI, the impact of GVC participation on ETFP was mainly stable in two district systems with the influence coefficients of 12.5704 and -18.0443 , respectively. The results indicated that the GVC participation first had positive promotion on ETFP and then suppressed ETFP. From the regression results of the benchmark GVC participation model, in the early embedding stage into the GVC, China was exposed to the advanced technology of developed countries and obtained the technology spillover from 
TABLE 1: Matched industries from multiple database sources.

\begin{tabular}{|c|c|c|}
\hline Industry name & Abbreviation $^{1}$ & Industry code \\
\hline Extractive industry & EI & c4 \\
\hline Food manufacturing industry & FMI & c5 \\
\hline Textile manufacturing industry & $\mathrm{TM}$ & c6 \\
\hline Wood-processing industry & WPI & c7 \\
\hline Paper making industry & PMI & c8 \\
\hline Printing industry & PI & c9 \\
\hline Petroleum processing and coking and nuclear material process & PCNP & $\mathrm{c} 10$ \\
\hline Chemical raw material & CRM & c11 \\
\hline Medical industry & MI & $\mathrm{c} 12$ \\
\hline Rubber and plastic products & $\mathrm{RPP}$ & $\mathrm{c} 13$ \\
\hline Nonmental mineral product industry & NMPI & $\mathrm{c} 14$ \\
\hline Basic metalwork & $\mathrm{BM}$ & c15 \\
\hline Metal manufacturing industry & MMI & c16 \\
\hline Computer telecommunication and other electronic equipment & CTEE & $\mathrm{c} 17$ \\
\hline Manufacturing industry of electronic machine and equipment & MIEE & $\mathrm{c} 18$ \\
\hline Machinery manufacturing enterprises & MME & c19 \\
\hline Transportation manufacturing industry & TMI & $\mathrm{c} 20$ \\
\hline Furniture manufacturing industry & FM & c22 \\
\hline Production and supply of electric power and heat power & PSEH & $\mathrm{c} 24$ \\
\hline Water production and supply sector & WPS & c25 \\
\hline
\end{tabular}

${ }^{1}$ The abbreviations in Figures 1 and 3 are the same as here.

TABLE 2: Linear test and residual nonlinear test results.

\begin{tabular}{lcccc}
\hline Test types & Statistics & GVC & GVC_S & GVC_S \\
\hline Linear test: & & $16.916^{* * *}$ & $12.338^{* *}$ & $14.573^{* *}$ \\
H0: $r=0$ & LM & $(0.005)$ & $(0.030)$ & $(0.012)$ \\
H1: $r=1$ & & $3.248^{* * *}$ & $2.317^{* *}$ & $2.767^{* *}$ \\
& LMF & $(0.008)$ & $(0.045)$ & $(0.019)$ \\
& & $17.601^{* * *}$ & $12.697^{* * *}$ & $15.078^{* * *}$ \\
& LRT & $(0.003)$ & $(0.026)$ & $(0.010)$ \\
Residual nonlinear & & & & \\
test: & LM & 6.118 & 6.701 & 4.614 \\
H0: $r=1$ & & $(0.295)$ & $(0.244)$ & $(0.465)$ \\
H1: $r=2$ & LMF & 1.058 & 1.162 & 0.793 \\
& & $(0.385)$ & $(0.329)$ & $(0.556)$ \\
& LRT & 6.204 & 6.805 & 4.663 \\
& & $(0.287)$ & $(0.236)$ & $(0.458)$ \\
\hline
\end{tabular}

Note. Null hypothesis H0: $r=0$, nonlinear effect. LM obeys $\chi^{2}$ distribution, LMF obeys $F(m K, T N-N-m(K+1))$ distribution, and $r$ is the number of transfer functions. $p$ values in parentheses, ${ }^{*} p<0.1,{ }^{* *} p<0.05$, and ${ }^{* * *} p<0.01$.

TABle 3: Optimal position.

\begin{tabular}{|c|c|c|c|c|}
\hline$m$ & Index & GVC & GVC_S & GVC_C \\
\hline \multirow[b]{2}{*}{$m=1$} & AIC & 1.637 & 1.665 & 1.647 \\
\hline & $\mathrm{BIC}$ & 1.822 & 1.850 & 1.832 \\
\hline \multirow{2}{*}{$m=2$} & AIC & 1.723 & 1.742 & 1.738 \\
\hline & BIC & 1.924 & 1.943 & 1.939 \\
\hline \multicolumn{2}{|c|}{ Conclusion } & $r=1 ; m=1$ & $r=1 ; m=1$ & $r=1 ; m=1$ \\
\hline
\end{tabular}

developed countries, thus promoting the improvement of ETFP. However, with the deepening of the embedding degree into the GVC, the technology spillover welfare of developed countries was gradually weakened. Although participation in the GVC has continuously expanded the production scale of various industries in China, the crude production mode has not brought about the improvement of
TABLE 4: Regression results.

\begin{tabular}{|c|c|c|c|c|}
\hline Variables & Index & GVC & GVC_S & GVC_C \\
\hline \multirow{2}{*}{$\begin{array}{l}\text { GVC } \\
\text { participation }\end{array}$} & $\beta_{0}^{\prime}$ & $\begin{array}{l}12.5704 \\
(1.5750)\end{array}$ & $\begin{array}{c}5.0510 \\
(0.3853)\end{array}$ & $\begin{array}{c}46.1198^{* *} \\
(2.3626)\end{array}$ \\
\hline & $\beta_{1}^{\prime}$ & $\begin{array}{c}-30.6157^{* * *} \\
(-3.7527)\end{array}$ & $\begin{array}{c}-36.7576^{* * *} \\
(-2.8176)\end{array}$ & $\begin{array}{c}-72.6892^{* * *} \\
(-4.0474)\end{array}$ \\
\hline \multirow{2}{*}{ EX } & $\beta_{0}^{\prime}$ & $\begin{array}{l}0.5293^{* *} \\
(2.1006)\end{array}$ & $\begin{array}{c}0.7227^{* * *} \\
(2.6010)\end{array}$ & $\begin{array}{l}0.5620^{*} \\
(1.6570)\end{array}$ \\
\hline & $\beta_{1}^{\prime}$ & $\begin{array}{c}-1.9800^{* * *} \\
(-3.1094)\end{array}$ & $\begin{array}{c}-2.3577^{* * *} \\
(-3.1786)\end{array}$ & $\begin{array}{l}-1.5121^{* *} \\
(-2.0465)\end{array}$ \\
\hline \multirow{2}{*}{ FDI } & $\beta_{0}^{\prime}$ & $\begin{array}{l}-0.2794 \\
(-0.4641)\end{array}$ & $\begin{array}{c}0.0780 \\
(0.1484)\end{array}$ & $\begin{array}{l}-0.0829 \\
(-0.1209)\end{array}$ \\
\hline & $\beta_{1}^{\prime}$ & $\begin{array}{c}4.0035^{* * *} \\
(4.0065)\end{array}$ & $\begin{array}{c}3.8153^{* * *} \\
(3.5004)\end{array}$ & $\begin{array}{c}3.4186^{* * *} \\
(3.0739)\end{array}$ \\
\hline LnK & $\beta_{1}^{\prime}$ & $\begin{array}{c}0.1118 \\
(0.9911) \\
-0.3757^{* * *} \\
(-3.0804)\end{array}$ & $\begin{array}{c}0.0711 \\
(0.6599) \\
-0.3479^{* * *} \\
(-2.7774)\end{array}$ & $\begin{array}{c}0.0844 \\
(0.7016) \\
-0.3419^{* *} \\
(-2.5059)\end{array}$ \\
\hline \multirow{6}{*}{ LnL } & $\begin{array}{l}\beta_{0}^{\prime} \\
\beta_{1}^{\prime}\end{array}$ & $\begin{array}{c}-0.3172^{*} \\
(-1.9272) \\
-0.0068 \\
(-0.0355)\end{array}$ & $\begin{array}{c}-0.5296^{* * *} \\
(-3.2103) \\
0.2447 \\
(1.2783)\end{array}$ & $\begin{array}{c}-0.3319^{* *} \\
(-2.1628) \\
-0.0520 \\
(-0.2913)\end{array}$ \\
\hline & $c_{1}$ & 5.0163 & 5.0955 & 5.0589 \\
\hline & $\gamma_{1}$ & 2.964 & 1.4024 & 4.7395 \\
\hline & RSS & 953.749 & 980.776 & 963.547 \\
\hline & AIC & 1.637 & 1.665 & 1.647 \\
\hline & BIC & 1.822 & 1.850 & 1.832 \\
\hline
\end{tabular}

Note. $t$ statistics in parentheses, ${ }^{*} p<0.1,{ }^{* *} p<0.05$, and ${ }^{* * *} p<0.01$.

the ETFP. Instead, the excessive consumption of energy has led to a decline in ETFP.

Secondly, from the perspective of the shallow GVC participation model, the impact of shallow GVC participation on ETFP had a single threshold characteristic. When the logarithm of FDI was less than 5.0955, the participation of shallow GVC can promote the total-factor energy productivity $\left(\beta_{0}^{\prime}=5.0510>0\right)$. When the logarithm of foreign 
direct investment reached the threshold of 5.0955, the shallow GVC participation had a negative impact on ETFP with the influence coefficient of -13.3278 $(5.0510-36.7576 \times 0.5)$. When the threshold was completely above 5.0955 , the impact of shallow GVC participation on ETFP was stabilized at -31.7066 (5.0510 - 36.7576) and was significant at a significance level of $1 \%$. The empirical results of the shallow GVC participation model showed that with the continuous increase of foreign direct investment, the impact of shallow GVC participation on ETFP was mainly stable in two district systems, and the influence coefficients were 5.0510 and -31.7066 for the lowand the high-zone districts, respectively. The results proved the shallow GVC participation first promoted ETFP and then suppressed ETFP, which was consistent with the regression result of benchmark GVC participation.

Thirdly, the impact of deep GVC participation on ETFP also exhibited a single threshold characteristic. When the logarithm of FDI was less than 5.0589, the deep GVC participation can promote the total-factor energy productivity $\left(\beta_{0}^{\prime}=46.1198>0\right)$, and the promotion effect was significant at a significance level of $5 \%$. When the logarithmic value of FDI reached the threshold of 5.0589, the influence coefficient of deep GVC participation on ETFP was decreased to $-9.7752(46.1198-72.6892 \times 0.5)$. When the threshold was completely above 5.0589 , the effect of the deep GVC participation on ETFP turned negative and was stabilized at $-26.5694(46.1198-72.6892)$, and the negative effect was significant at a significance level of $1 \%$. The empirical results of the deep GVC participation model showed that with the continuous increase of FDI, the impact of deep GVC participation on ETFP was mainly stable in two district systems (low district system and high district system), with the corresponding influence coefficients of 46.1198 and -26.5694 , respectively. The results proved that the deep GVC participation first promoted the ETFP and then suppressed ETFP, which was consistent with the regression result of benchmark GVC participation. However, unlike the benchmark GVC participation regression model, the deep GVC participation had a more significant promotion effect on ETFP before it exceeded the threshold, indicating that deep GVC participation had greater technology spillover effects.

Finally, from the perspective of control variables, in the benchmark GVC participation model, the impact of exports on ETFP was mainly stable in two districts with the impact coefficients of 0.5293 and -1.4507 , respectively. In the shallow GVC participation model, the impact coefficients of exports on ETFP in the two stable zones were 0.7227 and -1.635 , respectively. In the deep GVC participation model, the influence coefficients in the districts were 0.5620 and -0.9501 , respectively. Therefore, regardless of the degree of participation in GVCs, the impact of exports on the totalfactor energy productivity was first positive and then negative. In the benchmark GVC participation model, the impact of FDI on ETFP was mainly stable in two districts, with the impact coefficients of -0.2794 and 3.7241 , respectively. In the shallow GVC participation mode, the impact coefficients in the two stable zones were 0.0780 and
3.8933, respectively. In the deep GVC participation model, the impact coefficients in the two stable zones were -0.0829 and 3.3257, respectively. From the three models, it can be seen that in the low-zone system, the influence of FDI on ETFP was inconsistent and insignificant, which indicated that the effect of FDI on ETFP was weak in the low-zone system. In the high-zone system, the effect of FDI on ETFP was significantly positive at a significance level of $1 \%$, which indicated that FDI had a more obvious technology spillover effect and a promoting impact on ETFP in the high-zone system. The impact of capital on ETFP was mainly stable in two districts. In the benchmark GVC participation model, the impact coefficients of capital on ETFP were 0.1118 and -0.2639 in the two stable districts, respectively. In the shallow GVC participation model, the impact coefficients in the two stable districts were 0.0711 and -0.2768 , respectively. In the deep GVC participation model, the impact coefficients in the two stable districts were 0.0844 and -0.2575 , respectively. The impact of capital on ETFP was first positive and then negative and was independent of the degree of participation in GVC. The impact of labor on ETFP was mainly stable in two districts. In the benchmark GVC participation model, the influence coefficients in the two stable districts were -0.3172 and -0.378 , respectively. In the shallow GVC participation model, the influence coefficients in the two stable zones were -0.5296 and -0.2849 , respectively. In the deep GVC participation model, the influence coefficients in the two stable zones were -0.3319 and -0.3839 , respectively. The results proved that the impact of exports on ETFP was always negative and irrelevant to the degree of participation in GVC.

4.3. Industry Heterogeneity Inspection. In order to analyze the difference in the impact of different types of industries embedded in GVCs on ETFP, this study further analyzed the industry heterogeneity of the impact of GVC participation on ETFP. According to the intensity of energy consumption in the industrial industry, the industrial industry was divided into high energy consumption industry and low energy consumption industry. Based on the test results, the models of both high and low energy consumption industries were single threshold model $(r=1$ and $m=1)$.

The impact of GVC participation on ETFP in high energy consumption industries was estimated, as shown in Table 5. When the logarithm of FDI was less than 3.7471, the participation of GVC can promote the ETFP $\left(\beta_{0}^{\prime}=20.5798>0\right)$. When the logarithm of FDI reached the threshold of 3.7471, the positive promotion effect of GVC participation on ETFP was decreased to 9.7617 $(20.5798-21.6362 \times 0.5)$. When the threshold was completely above 3.7471 , the impact of deep GVC participation on ETFP became negative and stable at -1.0564 (20.5798-21.6362), and ETFP was significant at a significance level of $1 \%$. The empirical results in Table 5 showed that the GVC participation in high energy consumption industries first promoted the ETFP and then inhibited the ETFP, indicating an inverted U-shaped relationship between the GVC participation and ETFP. The estimated results on 
TABLE 5: Regression results of the high energy consumption trade.

\begin{tabular}{|c|c|c|}
\hline Variables & Index & Influence coefficients \\
\hline \multirow{3}{*}{ GVC participation } & $\beta_{0}^{\prime}$ & $\begin{array}{c}20.5798^{* * *} \\
(2.9672)\end{array}$ \\
\hline & & $-21.6362^{* * *}$ \\
\hline & $\beta_{1}^{\prime}$ & $(-4.0975$ \\
\hline \multirow{4}{*}{ EX } & $\beta_{0}^{\prime}$ & $0.9073^{* * *}$ \\
\hline & $P_{0}$ & (2.7922) \\
\hline & $\beta_{1}^{\prime}$ & $-1.0745^{* * *}$ \\
\hline & & $(-3.0470)$ \\
\hline \multirow{3}{*}{ FDI } & $\beta_{0}^{\prime}$ & $\begin{array}{c}0.4041 \\
(0.5734)\end{array}$ \\
\hline & & 0.8830 \\
\hline & $P_{1}$ & $(1.2894)$ \\
\hline \multirow{4}{*}{ LnK } & $\beta_{0}^{\prime}$ & 0.1340 \\
\hline & 80 & $(1.1967)$ \\
\hline & $\beta^{\prime}$ & $-0.2170^{*}$ \\
\hline & $P_{0}$ & $(-1.9066)$ \\
\hline \multirow{9}{*}{ LnL } & $\beta_{0}^{\prime}$ & -0.0646 \\
\hline & $P_{0}$ & $(-0.3042)$ \\
\hline & $\beta^{\prime}$ & -0.2009 \\
\hline & $P_{1}$ & $(-0.7850)$ \\
\hline & $c_{1}$ & 3.7471 \\
\hline & $\gamma_{1}$ & 9.9183 \\
\hline & RSS & 88.864 \\
\hline & AIC & 0.131 \\
\hline & BIC & 0.425 \\
\hline
\end{tabular}

Note. $t$ statistics in parentheses; ${ }^{*},{ }^{* *}$, and ${ }^{* * *}$ distributions represent significant levels of $10 \%, 5 \%$, and $1 \%$.

the impact of GVC participation on ETFP in low energy industries are shown in Table 6. The impact of GVC participation in low energy industries on ETFP was mainly stable in the two districts with the coefficients of -9.5103 and -1.6584 , respectively. However, the impact coefficients were not significant in both districts, indicating that the impact of GVC participation on ETFP is more obvious for the high energy industry. The phenomenon was mainly due to the fact that China has always been at the low and mid-end of the "smile curve" of the GVC and has mostly engaged in simple assembly and processing since participating in the GVC. Although China has obtained technology spillovers from developed countries and improved its technological level, it is still "low-locked" because developed countries often keep core technologies at home. The increase in the total-factor energy productivity brought by technological progress was no longer sustained. On the other hand, after participating in the GVC, China's foreign trade volume and FDI have both increased significantly and subsequently consumed a large amount of energy resources. When the technological progress effect of participating in the GVC was less than the scale effect, the ETFP would decline, which was more prominent in high energy-consuming industries.

4.4. Robustness Test. In order to test the robustness of the nonlinear effect between GVC embedding and ETFP, an exogenous control variable (labor) was removed in the benchmark model based on the previous study by Wang Xin [32]. The linear and residual nonlinear tests were performed
TABLE 6: Regression results of the low energy consumption trade.

\begin{tabular}{lcc}
\hline Variables & Index & Influence coefficients \\
\hline \multirow{4}{*}{ GVC participation } & $\beta_{0}^{\prime}$ & -9.5103 \\
& & $(-0.6423)$ \\
& $\beta_{1}^{\prime}$ & 7.8519 \\
EX & $\beta_{0}^{\prime}$ & $(0.4973)$ \\
& & $3.2231^{* * *}$ \\
& $\beta_{1}^{\prime}$ & $(4.5662)$ \\
FDI & $\beta_{0}^{\prime}$ & $2.2820^{* * *}$ \\
& & $(2.6580)$ \\
& $\beta_{1}^{\prime}$ & $-1.4570^{* * *}$ \\
LnK & $\beta_{0}^{\prime}$ & $(-2.0719)$ \\
& & $-3.8082^{* * *}$ \\
& $\beta_{0}^{\prime}$ & $(-3.0820)$ \\
& $\beta_{0}^{\prime}$ & -0.1950 \\
& $\beta_{1}^{\prime}$ & $(-0.2480)$ \\
& $c_{1}$ & -0.0271 \\
& $\gamma_{1}$ & $(0.0342)$ \\
& RSS & $-0.7824^{*}$ \\
& AIC & $(-1.9158)$ \\
& BIC & 0.6392 \\
& & $(1.5425)$ \\
& & 4.3994 \\
& & 16.6300 \\
& & 275.038 \\
& & 1.260 \\
& & 1.555 \\
& &
\end{tabular}

Note. $t$ statistics in parentheses; ${ }^{*}{ }^{* *}$, and ${ }^{* * *}$ distributions represent significant levels of $10 \%, 5 \%$, and $1 \%$.

TABLE 7: Robustness test.

\begin{tabular}{lcc}
\hline Variables & Index & Influence coefficients \\
\hline \multirow{4}{*}{ GVC participation } & $\beta_{0}^{\prime}$ & $(1.0584)$ \\
& & $-25.2235^{* * *}$ \\
& $\beta_{1}^{\prime}$ & $(-3.2869)$ \\
EX & $\beta_{0}^{\prime}$ & $0.5618^{* * *}$ \\
& & $(2.4410)$ \\
& $\beta_{1}^{\prime}$ & $-2.4362^{* * *}$ \\
FDI & $\beta_{0}^{\prime}$ & $(-3.7484)$ \\
& & -0.1875 \\
& $\beta_{1}^{\prime}$ & $(-0.3399)$ \\
& $\beta_{0}^{\prime}$ & $4.0905^{* * *}$ \\
& & $(3.8461)$ \\
& $\beta_{0}^{\prime}$ & 0.0765 \\
LnK & $C_{1}$ & $(0.7088)$ \\
& $\Gamma_{1}$ & $-0.3412^{* * *}$ \\
& RSS & $(-2.8174)$ \\
& AIC & 5.0955 \\
& BIC & 1.4253 \\
& & 981.130 \\
& & 1.637 \\
& & 1.792
\end{tabular}

Note. $t$ statistics in parentheses; ${ }^{* * *}$, and $^{* * *}$ distributions represent significant levels of $10 \%, 5 \%$, and $1 \%$.

on the model, and the number of position parameters was determined. The test results were consistent with the conclusion of the benchmark model, which proved that removing an exogenous control variable did not change the number of transformation functions or the number of 
transformation position parameters of the model. The corresponding robustness test results are shown in Table 7 . From Table 7, the sign (positive or negative) and significance of the influence coefficients of the core explanatory variables (GVC participation) in different regions in the model were consistent with the regression results of the benchmark model in Table 4, indicating the regression results obtained by the PSTR model were robust.

\section{Research Conclusions and Policy Recommendations}

In this study, we used macrodata from China's industrial sectors from 2001 to 2014 to analyze the impact of GVC embedding on the total-factor energy productivity. The DEA-Malmquist index method was used to calculate the ETFP of the industrial industry. The GVC participation was divided into two categories, i.e., shallow and deep GVC production activities, and the corresponding participation degrees were measured.

The following conclusions can be drawn from the research results: firstly, the ETFP of all the industries except for the pharmaceutical manufacturing industry was less than 1 , indicating that the ETFP has been declined in most Chinese industrial sectors, especially in the power, heat production and supply, metal products, extractive industries, and other high energy consumption industries.

Secondly, both the shallow-level and deep-level GVC participation models had a single threshold effect on ETFP. The difference between the two models was that before the threshold was exceeded, the promotion effect of deep GVC participation was more significant, which indicated that the technology spillover effect of deep GVC participation was greater.

Thirdly, the impact of exports on ETFP was first positive and then negative; meanwhile, it was not relevant to the degree of GVC participation. The technological spillover effect of FDI was more obvious in high-tech areas, and it had a promotion effect on ETFP. The impact of capital on ETFP was first positive and then negative, regardless of the degree of participation in the GVC. The impact of exports on ETFP was always negative, regardless of the degree of participation of GVC.

In this study, many rigid constraints such as resource pressure and environmental pressure were comprehensively considered. In order to further promote the improvement of total-factor energy productivity in the industrial sectors, the following recommendations are proposed:

(1) Government departments should actively promote a new round of opening up, continue to increase the depth and breadth of the GVC embedding, make full use of the positive effect of GVC embedding on the ETFP, and continuously improve the technological level and innovation capabilities of companies, especially in light industries such as food, beverage, and tobacco products manufacturing, which are more affected by economic fluctuations.

(2) Government should emphasize on the positive effect of FDI on the ETFP in the industrial sector. On the one hand, we should change the mode of attracting investment, thus actively guiding the transition of FDI from high pollution and high energy consumption industries to low pollution and low energy consumption industries. On the other hand, government should actively encourage the industrial industry to participate in the international division of labor in the form of characteristic industrial clusters. Thus, the domestic-funded enterprises in the cluster and the foreign-funded enterprises can form a closely complementary, inner, and interconnection clean production system, which can strengthen FDI's domestic roots and improve industrial association degree, making the domestic and foreign enterprises play the dual role in promoting total-factor energy productivity.

(3) While promoting the industrial industry to deepen the GVC embedding, government departments should pay attention to the industry heterogeneity of the impact of GVC participation on the ETFP. On the one hand, governments at all levels should increase their support for high-end equipment manufacturing, information technology, energy-saving and environmental protection industries, new energy industries, and new materials industries and give reasonable preferential policies. On the other hand, for some resource-based industries and high energy consumption industries, the corresponding supervision mechanism should be further improved, the negative list system for industry access should be completed, and the entry threshold for the industry should be raised. At the same time, specifications such as environmental impact assessment and energy consumption should be clarified to reduce both the amount and the intensity of the consumed energy in the industrial industry and enhance the core competitiveness of the industry.

This paper has some limitations and can be expanded through extensive research. Firstly, from the vertical perspective, this paper discussed the impact of GVC embedding on ETFP from the national level. At present, the development of central, eastern, and western parts of China is still uneven, and thus, the impact of GVC on ETFP can be studied from the regional perspective. Secondly, from the horizontal perspective, due to data limitations, the influence of GVC embedding on ETFP of other countries can be studied for comparison with China. Finally, most of the current literature mainly studies the impact of GVC on ETFP from an empirical perspective, while theoretical research still needs to be developed and improved.

\section{Data Availability}

The sequence data used to support the findings of this study are available from the corresponding author upon request.

\section{Conflicts of Interest}

The authors declare that they have no conflicts of interest. 


\section{References}

[1] Z. Peng and B. Zhang, "The evolution of China's international division of labor income and its determinant," China Industrial Economy, vol. 6, pp. 62-80, 2018.

[2] F. Zhang and K. S. Gallagher, "Innovation and technology transfer through global value chains: evidence from China's PV industry," Energy Policy, vol. 94, pp. 191-203, 2016.

[3] J. Yu, "Does the embeddedness of the global value chain affect the intensity of enterprises' pollution discharge: a microanalysis based on the PSM matching and doubled method," International Trade, vol. 12, pp. 59-69, 2017.

[4] Q. Huang, J. Hu, and X. Chen, "Environmental regulation and green TFP: a dilemma or a win-win?" China Population Resources and Environment, vol. 28, no. 11, pp. 140-149, 2018.

[5] H. Egger and P. Egger, "Labor market effects of outsourcing under industrial interdependence," International Review of Economics and Finance, vol. 14, no. 3, 2004.

[6] M. Amiti and S. J. Wei, "Service offshoring and productivity: evidence from the United State," Nber Working Papers, vol. 14, 2006.

[7] Y. Chen, "Comparing North-South technology transfer and South-South technology transfer: the technology transfer impact of Ethiopian Wind Farms," Energy Policy, vol. 116, pp. 1-9, 2018.

[8] D. Flent and S. Ponte, "Least-developed countries in a world of global value chains: are wto trade negotiations helping," World Development, vol. 94, pp. 366-374, 2017.

[9] B. Simon, T. Hansen, and O. Solér, "Value chain structures that define European cellulosic Ethanol production," Sustainability, vol. 9, no. 1, p. 118, 2017.

[10] J. M. Dean and M. E. Lovely, "Trade growth, production fragmentation, and China's environment," NBER Working Paper No:13860, vol. 94, 2008.

[11] V. De Marchi, M. Eleonora Di, and S. Ponte, "The greening of global value chains: insights from the furniture industry," Competition and Change, vol. 17, no. 4, 2013.

[12] P. Montalbano, S. Nenci, and C. Pietrobelli, "Opening and linking up: firms, GVCs, and productivity in Latin America," Small Business Economics, vol. 50, no. 4, pp. 917-935, 2018.

[13] J. Ge, Y. Fu, R. Xie, Yu Liu, and W. Mo, "The effect of GVC embeddedness on productivity improvement: from the perspective of R\&D and government subsidy," Technological Forecasting and Social Change, vol. 135, pp. 22-31, 2018.

[14] Z. Qiu, "The impact of international vertical specialization on China's $\mathrm{CO}_{2}$ emissions," Eco-Economy, vol. 10, pp. 28-32, 2012.

[15] F. Hu, "Environmental effects of manufacturing global value chain division and China's countermeasures," Exploration of Economic Issues, vol. 3, pp. 151-155, 2016.

[16] C. Liu and X. Zhao, "Is there industrial heterogeneity in the strong "Porter Hypothesis"? Based on the perspective of industrial carbon intensity segmentation," China Population, Resources and Environment, vol. 27, no. 6, pp. 1-9, 2017.

[17] S. Chen, "Assessment of the low carbon economy transition process in different regions of China," Economic Research, vol. 47, no. 8, pp. 32-44, 2012.

[18] Y. Yu, Y. Zhang, and X. Yang, "Analysis of innovation input structure and total factor productivity from the perspective of innovation value chain," Sankei Review, vol. 8, no. 3, pp. 31-46, 2017.

[19] Z. Wang, S.-J. Wei, X. Yu, and K. Zhu, "Measures of participation in global value chains and global business cycles," NBER Working Paper 23222, vol. 23, 2017.
[20] S. Wang and L. Zheng, "Effects of global value chain embedded features on the differentiation of export technology complexity," Quantitative Economics, Technology and Economy Research, vol. 36, no. 5, pp. 65-82, 2019.

[21] A.'es Gonz'alez, Panel Smooth Transition Regression Model, Banco de la Republica, Bogota, Colombia, 2017.

[22] G. Arce, M. A. Cadarso, L. A. López et al., "Indirect Pollution Haven Hypothesis in a Context of Global Value Chain," in Proceedings of the Final WIOD Conference: Causes and Consequences of Globalization, Groningen, The Netherlands, 2012.

[23] C. Sun, Z. Li, T. Ma, and R. He, "Carbon efficiency and international specialization position: evidence from global value chain position index of manufacture," Energy Policy, vol. 128, pp. 235-242, 2019.

[24] Z. Wang, Characterizing Global Value Chains, University of International Business and Economics \& George Mason University, 2016.

[25] L. Ren and R. Min, "Cluster and co-located cluster effects: An empirical study of six Chinese city regions," Research Policy, vol. 45, 2016.

[26] Ü. Arslan and M. Ö. Güngör, "The effect of brand value on economic growth: a multinational analysis," European Research on Management and Business Economics, vol. 25, pp. 1-7, 2019.

[27] S. He, Z. Khan, and O. Shenkar, "Subsidiary capability upgrading under emerging market acquirers," Journal of World Business, vol. 53, no. 2, pp. 248-262, 2018.

[28] Y. Lu, H. Shi, W. Luo, and B. Liu, "Productivity, financial constraints, and firms' global value chain participation: evidence from China," Economic Modelling, vol. 73, pp. 184-194, 2018.

[29] C.-Y. Chiu, C.-C. Lin, and C.-H. Yang, "Technological catching-up between two ASEAN members and China: a metafrontier approach," China Economic Review, vol. 54, pp. 12-25, 2019.

[30] S. Kergroach, "National innovation policies for technology upgrading through GVCs: a cross-country comparison," Technological Forecasting and Social Change, vol. 145, pp. 258-272, 2019.

[31] Y. Lu, "China's electrical equipment manufacturing in the global value chain: a GVC income analysis based on World Input-Output Database (WIOD)," International Review of Economics \& Finance, vol. 52, pp. 289-301, 2017.

[32] X. Wang and H. Yao, "The non-linear dynamic effect of ofdi on regional technology innovation in the yangtze river delta: a PSTR model test based on absorptive capacity," World Economic Research, vol. 11, pp. 86-100, 2016. 